\title{
Lead Slowing Down Spectrometer Research Plans
}

$\begin{array}{ll}\text { GA Warren } & \text { A Weltz }^{2} \\ \text { J Kulisek } & \text { J Harris }^{3} \\ \text { V Gavron } & \text { T Stewart }^{3} \\ \text { Y Danon } & \end{array}$

March 2013

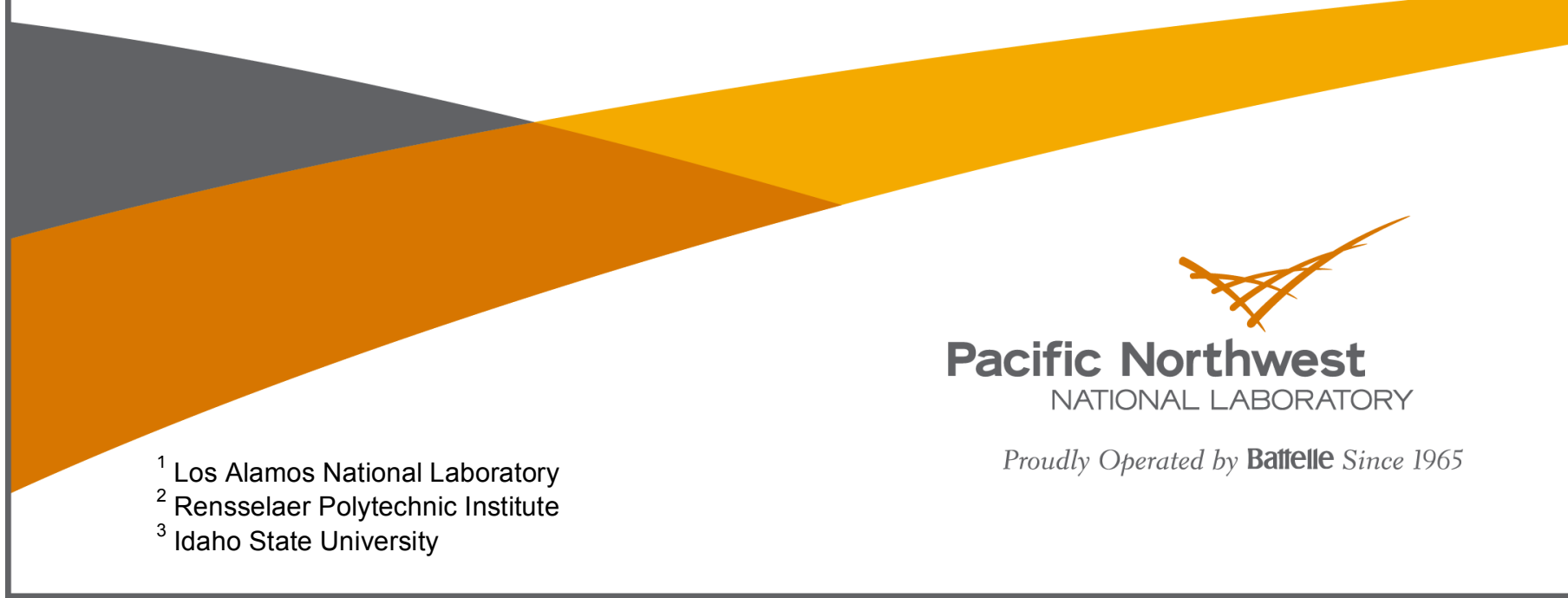




\title{
DISCLAIMER
}

This report was prepared as an account of work sponsored by an agency of the United States Government. Neither the United States Government nor any agency thereof, nor Battelle Memorial Institute, nor any of their employees, makes any warranty, express or implied, or assumes any legal liability or responsibility for the accuracy, completeness, or usefulness of any information, apparatus, product, or process disclosed, or represents that its use would not infringe privately owned rights. Reference herein to any specific commercial product, process, or service by trade name, trademark, manufacturer, or otherwise does not necessarily constitute or imply its endorsement, recommendation, or favoring by the United States Government or any agency thereof, or Battelle Memorial Institute. The views and opinions of authors expressed herein do not necessarily state or reflect those of the United States Government or any agency thereof.

\author{
PACIFIC NORTHWEST NATIONAL LABORATORY \\ operated by \\ BATTELLE \\ for the \\ UNITED STATES DEPARTMENT OF ENERGY \\ under Contract DE-AC05-76RL01830 \\ Printed in the United States of America
Available to DOE and DOE contractors from the Office of Scientific and Technical Information, P.O. Box 62, Oak Ridge, TN 37831-0062; ph: (865) 576-8401 fax: $(865)$ 576-5728
email: reports $\boldsymbol{a}$ adonis.osti.gov \\ Available to the public from the National Technical Information Service \\ 5301 Shawnee Rd., Alexandria, VA 22312 \\ ph: (800) 553-NTIS (6847) \\ email: orders $\omega$ ntis.gov $<$ http://www.ntis.gov/about/form.aspx $>$ \\ Online ordering: http://www.ntis.gov
}




\section{Lead Slowing Down Spectrometer Research Plans}

\begin{tabular}{|c|c|}
\hline GA Warren & A Weltz ${ }^{2}$ \\
\hline J Kulisek & $\mathrm{J} \mathrm{Harris}^{3}$ \\
\hline V Gavron ${ }^{1}$ & T Stewart ${ }^{3}$ \\
\hline
\end{tabular}

March 2013

Prepared for

the U.S. Department of Energy

under Contract DE-AC05-76RL01830

Pacific Northwest National Laboratory

Richland, Washington 99352

\footnotetext{
${ }^{1}$ Los Alamos National Laboratory

${ }^{2}$ Rensselaer Polytechnic Institute

${ }^{3}$ Idaho State University
} 



\section{Executive Summary}

The MPACT-funded Lead Slowing Down Spectrometry (LSDS) project has been evaluating the feasibility of using LSDS techniques to assay fissile isotopes in used nuclear fuel assemblies. The approach has the potential to provide considerable improvement in the assay of fissile isotopic masses in fuel assemblies compared to other non-destructive techniques in a direct and independent manner. The collaboration has been working toward a goal of conducting Technical Ready Level (TRL) 5 measurements in 2014. To achieve the "operationally relevant environment" of a TRL 5 demonstration, measurements should be conducted on used-fuel assemblies. While it is possible for many of the components of the planned demonstration to be ready by 2014, a used fuel assembly for the measurements will not be available to us within that timeframe. The LSDS collaboration recommends, as an alternative, that the next step in empirically testing feasibility is to conduct measurements on fresh fuel assemblies to investigate self-attenuation and fresh mixed-oxide (MOX) fuel rodlets so we may better understand extraction of masses for ${ }^{235} \mathrm{U}$ and ${ }^{239} \mathrm{Pu}$. While progressing toward these goals, the collaboration also strongly suggests the continued development of enabling technology such as detector and algorithm development, which could provide significant performance benefits. 



\section{Acronyms and Abbreviations}

\begin{tabular}{|c|c|}
\hline DoD & Department of Defense \\
\hline FY & Fiscal year \\
\hline GWd/tHM & Gigawatt days per metric ton of heavy metal \\
\hline INL & Idaho National Laboratory \\
\hline INSEP & International Nuclear Safeguards Engagement Program \\
\hline ISU & Idaho State University \\
\hline LANL & Los Alamos National Laboratory \\
\hline LSDS & Lead Slowing-Down Spectrometer \\
\hline MCNP & Monte Carlo N-Particle Transport Code \\
\hline MOX & mixed-oxide \\
\hline MPACT & Material Protection And Control Technology \\
\hline NEUP & Nuclear Engineer University Programs \\
\hline NGSI & Next Generation Safeguards Initiative \\
\hline NRC & Nuclear Regulatory Commission \\
\hline PNNL & Pacific Northwest National Laboratory \\
\hline PWR & Pressurized water reactor \\
\hline RPI & Rensselaer Polytechnic Institute \\
\hline TRL & Technical Readiness Level \\
\hline $\mathrm{uDU}$ & Ultra-depleted uranium \\
\hline UNLV & University of Nevada Las Vegas \\
\hline
\end{tabular}





\section{Contents}

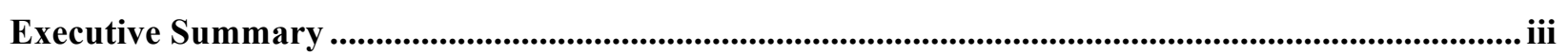

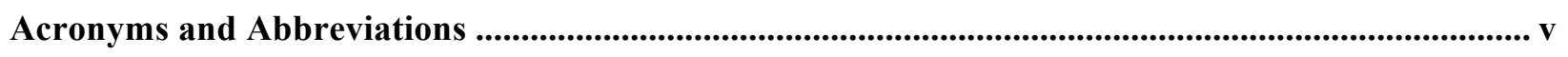

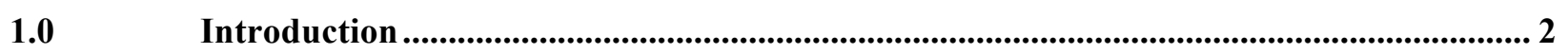

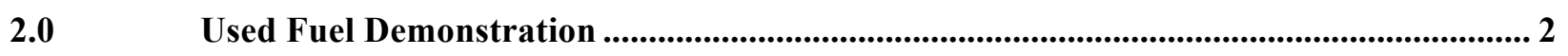

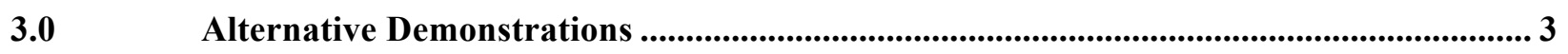

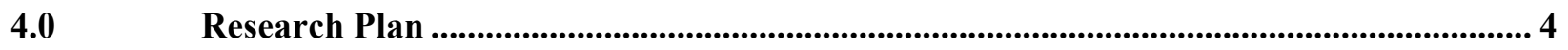

5.0 Value of Enabling Technology Research .................................................................................. 7

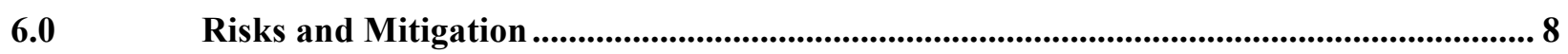

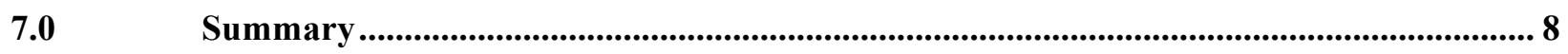

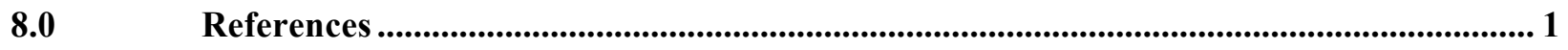




\subsection{Introduction}

Developing a method for the accurate, direct, and independent assay of the fissile isotopes in bulk materials (such as used fuel) from next-generation domestic nuclear fuel cycles is a goal of the Office of Nuclear Energy, Fuel Cycle R\&D, Material Protection and Control Technology (MPACT) Campaign. To meet this goal, MPACT supports a multi-institutional collaboration, of which Pacific Northwest National Laboratory (PNNL) is a part, to study the feasibility of Lead Slowing Down Spectroscopy (LSDS). This technique is an active, nondestructive assay method that has the potential to provide independent, direct measurement of plutonium and uranium isotopic masses in used fuel with an uncertainty considerably lower than the approximately $10 \%$ typical of today's confirmatory methods.

The LSDS project has been directed to work toward conducting a Technical Readiness Level (TRL) 5 demonstration in fiscal year 2014 (FY14). A TRL 5 demonstration is defined by U.S. Department of Defense (DoD) as a "component and/or breadboard validation in a relevant environment" (Lemnios 2011). The components required for an LSDS measurement include an intense pulsed neutron source $\left(\sim 10^{12} \mathrm{n} / \mathrm{s}\right.$ ), a large block ( $\sim 40$ metric tons) of high-purity lead, detectors to measure the fission neutrons emitted from the interrogated fuel, detectors to measure the neutron flux, and an analysis algorithm to interpret the data to extract the isotopic masses. Many of the components are actively under development and could potentially be ready by 2014 . The "relevant environment" for the demonstration would be established by the facility in which the measurements are conducted and by the sample measured. The ideal sample would be a used fuel assembly. Such a sample would enable a test of the LSDS technique that could study possible self-attenuation affects, ability to extract isotopic masses, and the impact of the radiation from the used fuel assembly on the detectors. The ideal facility would have access to used-fuel assemblies and be able to handle the used fuel assemblies in a manner that would enable LSDS measurements. The "relevant environment" creates the single greatest challenge to conduct a TRL 5 demonstration in FY14. This report documents those challenges, and presents an alternative path to continue to advance the understanding of applying LSDS techniques to assay of used fuel assemblies.

\subsection{Used Fuel Demonstration}

Used fuel assemblies present a number of challenges. The very high radiation dose of a used fuel assembly presents a major safety risk. For typical pressurized water reactor (PWR) spent fuel burnups (e.g., $33 \mathrm{GWd} / \mathrm{tHM}$ and $50 \mathrm{GWd} / \mathrm{tHM}$ ), the dose rate $1 \mathrm{~m}$ perpendicular to the assembly is over $10^{5}$ rem per hour, freshly discharged from the nuclear reactor. Even 100 years after discharge, the dose rate from a typical PWR spent fuel assembly at $1 \mathrm{~m}$ would still be approximately $100 \mathrm{rem}$ per hour, which is lethal to $50 \%$ of adults after three to four hours (IPFM 2012). Therefore, considerable shielding and safety precautions would be required, making handling the spent fuel costly.

Transportation within the U.S. is another challenge of used fuel assemblies. There is no clear path for long-term disposition of used fuel in the U.S. As a result, any given facility is unlikely to be willing to receive used fuel from another due to the potential long-term costs that would be incurred. Our search for a facility at which to conduct a TRL 5 demonstration was therefore limited to facilities that already had existing used fuel assemblies. The implication is that the measurement system would have to be 
transported to that facility, since the only two operational LSDS systems in the U.S. are at facilities with no used fuel assemblies.

Idaho National Laboratory (INL) is the only domestic facility that has access to used-fuel assemblies. However, INL does not have the used-fuel handling capabilities that would make them available for LSDS measurements. Thus, the facility search was broadened to include international facilities. Given the relatively limited time frame, the search for an international facility was restricted to those where a measurement was already planned in collaboration with the U.S. agency. The possibility of collaboration was discussed with the Next Generation Safeguards Initiative (NGSI); however, their international efforts are restricted by agreements that list specific measurement techniques, and injecting a new technique was not feasible given the relatively short time frames of both the NGSI effort and this effort (Humphrey 2012). Discussions were also held with International Nuclear Safeguards Engagement Program (INSEP) regarding possible support for an international collaborative effort. INSEP supports international cooperation for technologies at a higher technical readiness level than that of this project, so this path for seeking an international facility is not available.

The one remaining alternative for conducting LSDS measurements on used-fuel assemblies is the construction of a new domestic facility. Precedents exist at two sites for handling small solution-type samples of spent fuel in hot cells, which were built at the reprocessing facilities at Sellafield, United Kingdom, and La Hague, France. However, these laboratories took several years to become operational from the time they were approved for construction. For example, the on-site laboratory at La Hague was operational eight years after construction approval, involved several organizations, and required staff training (Daures et al. 2001). Thus this option, due to the expense and time frame, is also unsuitable for a TRL5 demonstration in FY14. Nonetheless, it might be worthwhile to assess whether or not there is a broader need for a domestic facility capable of handling assay research on used for assemblies to address possible longer range research needs.

\subsection{Alternative Demonstrations}

Since LSDS demonstration measurements on used fuel assemblies within the next few years is unrealistic, the question shifts to what demonstrations can be conducted to further research on the application of LSDS techniques for the extraction of fissile isotopic masses in used fuel assemblies. As an alternative, we are proposing a demonstration of the LSDS on a combination of fresh mixed-oxide (MOX) fuel and fresh $\mathrm{UO}_{2}$ fuel sub-assemblies. These measurements would enable the experimental validation of the technique on mixed U-Pu fuel as well as on the self-attenuation within the fuel assembly. These alternative measurements will provide the next step in building confidence that the LSDS technique will be able to extract fissile plutonium mass in used nuclear fuel.

Two LSDS instruments currently exist in the United States at linear particle accelerator facilities, one at Los Alamos National Laboratory (LANL) and one at Rensselaer Polytechnic Institute (RPI). At RPI, plans are underway to obtain and assay a fresh $\mathrm{UO}_{2}$ fuel assembly. RPI is currently waiting on licensing from the Nuclear Regulatory Commission (NRC) to ship the fresh fuel rods from their reactor site to the location of their LSDS. RPI has in its possession ${ }^{232} \mathrm{Th},{ }^{233} \mathrm{U},{ }^{235} \mathrm{U},{ }^{238} \mathrm{U}$ and ${ }^{239} \mathrm{Pu}$ fission chambers that are used in the current algorithms. A supply of well-characterized, fresh MOX fuel pins, containing varying known quantities of plutonium, exist at SCK $\bullet$ CEN in Belgium (Frazer 2012). The variety of isotopics available for the MOX rodlets will enable to use of some of the rodlets as a calibration set. 
Provided that these fuel rodlets can be obtained, current algorithms can be used to extract the fissile isotopic masses of ${ }^{235} \mathrm{U}$ and ${ }^{239} \mathrm{Pu}$. At this point, RPI believes that it can receive the necessary permits to receive and handle the MOX fuel. An alternative source of fresh MOX fuel at LANL was also identified; however, it is unlikely that this material will be available for project measurements in the time frame of this project. PNNL has also recently engaged INL to explore options of materials with a mixture of ${ }^{235} \mathrm{U}$ and ${ }^{239} \mathrm{Pu}$ that may be suitable for these measurements.

\subsection{Research Plan}

The collaboration recommends a three-year research plan. The proposed work can be broken down into four categories: fresh fuel demonstrations, MOX fuel demonstrations, algorithm-enabling technologies and detector-enabling technologies. The demonstration measurements will each consist of planning for the measurements, acquisition of the samples (including necessary licensing), conducting the measurements, and evaluating the results. Development of the algorithm enabling technology will continue, focusing on simplifying the application of the algorithms. The detector-enabling technology effort will develop ${ }^{238} \mathrm{U}$ fission chambers and ${ }^{4} \mathrm{He}$ scintillator detectors as fast neutron detectors. These detectors may be able to provide significant performance improvements over the planned ${ }^{232} \mathrm{Th}$ fission chambers. The responsibilities of the collaboration members are:

- PNNL: Collaboration leadership, algorithm development, evaluation of demonstration measurements

- LANL: Helium-4 detector development, algorithm development, evaluation of demonstration measurements

- RPI: Demonstration measurement execution, evaluation of demonstration measurements

- Idaho State University (ISU): Thorium-232 fission chamber development, testing and evaluation

- University of Nevada Las Vegas (UNLV): Uranium-238 fission chamber development, testing and evaluation

The approximate schedule for the research plan is below:

- Early FY14:

- PNNL seeks licenses, permissions to ship fresh MOX fuel from Belgium to RPI

- PNNL begins work refining algorithms

○ LANL begins work on ${ }^{4} \mathrm{He}$ detector

- ISU constructs large scale thorium fission chamber

- Mid FY14:

- RPI receives permission from the NRC to ship the fresh fuel pins to the measurement facility

○ UNLV receives ultra-depleted uranium (uDU)-plated foils for making a fission chamber

- Late FY14:

- RPI conducts LSDS measurements on various sized sub-assemblies to test selfattenuation

- ISU tests large scale thorium fission chamber

- LANL tests ${ }^{4} \mathrm{He}$ fast neutron detector

- UNLV completes characterization of uDU foils to ascertain level of ${ }^{235} \mathrm{U}$ 
- Early FY15:

○ RPI, LANL, PNNL complete analysis of fresh fuel assemblies measurements

- Mid FY15:

- Necessary permissions and licenses are in place for shipping the MOX fuel from Belgium to RPI

- Late FY15:

- UNLV completes construction of test uDU fission chamber

- Ship MOX fuel to RPI

- Early FY16:

- RPI conducts characterization measurements of MOX rodlets

- Mid FY16:

- RPI conduct LSDS measurements on MOX rodlets

- ISU tests large scale thorium fission chamber

- UNLV tests uDU fission chamber

- LANL tests ${ }^{4} \mathrm{He}$ fast neutron detector

- Late FY16:

$\circ$ RPI, LANL and PNNL complete analysis of fresh MOX measurements

The suggested budget for this work is provided in Table 1. The collaboration has submitted a proposal for Nuclear Engineering University Programs (NEUP) funding. If funded, the NEUP work would support the fresh MOX material measurements and the enabling technology development at the universities, while MPACT program would support the fresh fuel assembly measurement and the enabling technology development at the national laboratories. In the event that no NEUP funding is awarded, the "Total Funding" represents the level of MPACT funds requested to complete the scope of work.

This proposed plan has only a modest level of effort to handle the shipping and licensing issues related to the handling of the materials necessary for the measurements. No funding has been estimated for the cost of the material itself. It is also possible that the level of effort required to address the logistics for the material may exceed the modest estimate incorporated into the suggested budget below.

Table 1: Suggested Budget for Conducting LSDS Demonstration Measurements Assuming MPACT and NEUP Funding

\begin{tabular}{|r|r|r|r|r|r|}
\hline & \multicolumn{2}{|c|}{ MPACT Funding } & \multicolumn{2}{|c|}{ NEUP Funding } & \\
\hline FY14 & $\begin{array}{c}\text { Demonstration } \\
\text { Measurements }\end{array}$ & $\begin{array}{c}\text { Enabling } \\
\text { Technologies }\end{array}$ & $\begin{array}{r}\text { Demonstration } \\
\text { Measurements }\end{array}$ & $\begin{array}{c}\text { Enabling } \\
\text { Technologies }\end{array}$ & Total Funding \\
\hline PNNL & $\$ 94 \mathrm{~K}$ & $\$ 244 \mathrm{~K}$ & $\$ 10 \mathrm{~K}$ & \\
\hline LANL & $\$ 100 \mathrm{~K}$ & $\$ 35 \mathrm{~K}$ & $\$ 10 \mathrm{~K}$ & & $\$ 348 \mathrm{~K}$ \\
\hline
\end{tabular}


PNNL-22340

\begin{tabular}{|c|c|c|c|c|c|}
\hline RPI & $\$ 80 \mathrm{~K}$ & & $\$ 117 \mathrm{~K}$ & & \$197K \\
\hline ISU & & & & $\$ 65 \mathrm{~K}$ & $\$ 65 \mathrm{~K}$ \\
\hline UNLV & & & & $\$ 65 \mathrm{~K}$ & $\$ 65 \mathrm{~K}$ \\
\hline Total & $\$ 274 K$ & $\$ 594 K$ & \$137K & $\$ 130 \mathrm{~K}$ & $\$ 1,135 \mathrm{~K}$ \\
\hline FY15 & $\begin{array}{l}\text { Demonstration } \\
\text { Measurements }\end{array}$ & $\begin{array}{c}\text { Enabling } \\
\text { Technologies }\end{array}$ & $\begin{array}{l}\text { Demonstration } \\
\text { Measurements }\end{array}$ & $\begin{array}{c}\text { Enabling } \\
\text { Technologies }\end{array}$ & Total Funding \\
\hline PNNL & \$154K & $\$ 250 \mathrm{~K}$ & $\$ 10 \mathrm{~K}$ & & $\$ 414 K$ \\
\hline LANL & \$100K & $\$ 200 \mathrm{~K}$ & $\$ 10 \mathrm{~K}$ & & $\$ 310 \mathrm{~K}$ \\
\hline RPI & $\$ 80 \mathrm{~K}$ & & $\$ 117 \mathrm{~K}$ & & \$197K \\
\hline ISU & & & & $\$ 65 \mathrm{~K}$ & $\$ 65 \mathrm{~K}$ \\
\hline UNLV & & & & $\$ 65 \mathrm{~K}$ & $\$ 65 \mathrm{~K}$ \\
\hline Total & $\$ 334 \mathrm{~K}$ & $\$ 450 \mathrm{~K}$ & \$137K & $\$ 130 \mathrm{~K}$ & $\$ 1051 \mathrm{~K}$ \\
\hline FY16 & $\begin{array}{l}\text { Demonstration } \\
\text { Measurements }\end{array}$ & $\begin{array}{c}\text { Enabling } \\
\text { Technologies }\end{array}$ & $\begin{array}{l}\text { Demonstration } \\
\text { Measurements }\end{array}$ & $\begin{array}{c}\text { Enabling } \\
\text { Technologies }\end{array}$ & Total Funding \\
\hline PNNL & \$114K & \$257K & $\$ 10 \mathrm{~K}$ & & $\$ 381 \mathrm{~K}$ \\
\hline LANL & \$100K & $\$ 200 \mathrm{~K}$ & $\$ 10 \mathrm{~K}$ & & $\$ 310 \mathrm{~K}$ \\
\hline RPI & & & \$117K & & $\$ 117 \mathrm{~K}$ \\
\hline ISU & & & & $\$ 65 \mathrm{~K}$ & $\$ 65 \mathrm{~K}$ \\
\hline UNLV & & & & $\$ 65 K$ & $\$ 65 \mathrm{~K}$ \\
\hline Total & $\$ 214 K$ & $\$ 457 \mathrm{~K}$ & $\$ 137 \mathrm{~K}$ & $\$ 130 \mathrm{~K}$ & $\$ 938 \mathrm{~K}$ \\
\hline
\end{tabular}




\subsection{Value of Enabling Technology Research}

Two classes of enabling technology could significantly impact the feasibility of using the LSDS approach to assay used fuel assemblies: further refined algorithms and the development of fast neutron detectors. The collaboration plans to consider two types of fast neutron detectors, a ${ }^{238} \mathrm{U}$ fission chamber and a ${ }^{4} \mathrm{He}$ scintillator. The potential benefits of each of these technologies are discussed below.

The current algorithms have been tested against a wide range of Monte Carlo N-Particle Transport Code (MCNP) simulations and a limited amount of measured data. These evaluations have demonstrated the potential for assaying isotopic fissile mass to less than 3\% uncertainties in fuel assemblies. However, the current algorithms have several specific shortcomings. First, the algorithms must be calibrated using approximately five well-characterized fuel assemblies. In addition, the algorithms require the use of fission chambers containing isotopes of each of the fissile isotopes of interest. As a result, one would require ${ }^{235} \mathrm{U},{ }^{239} \mathrm{Pu}$ and ${ }^{241} \mathrm{Pu}$ fission chambers. PNNL has been working on algorithms that do not require the plutonium fission chambers, and it is possible that if one constrains the set of possible used fuel assemblies, a smaller calibration set will be required. Alternatively, we may consider a completely new approach that is perhaps a hybrid of measurements and modeling, which does not require a large calibration set.

Part of the necessary instrumentation for the LSDS is detectors that are sensitive only to fast neutrons. These detectors monitor the rate at which fissions are generated in the used fuel assembly. The current plan is to develop ${ }^{232} \mathrm{Th}$ fission chambers for this purpose, a well-established approach. The collaboration recommends the pursuit of two alternative approaches: $\mathrm{a}^{238} \mathrm{U}$ fission chamber and a ${ }^{4} \mathrm{He}$ recoil scintillator.

The advantage of the ${ }^{238} \mathrm{U}$ fission chamber is that the cross section for fast neutrons is roughly four times larger than that for ${ }^{232} \mathrm{Th}$. As a result, it may be possible to use fewer detectors, less intense neutron sources, shorter measurement times, or some combination of those three. The challenges for ${ }^{238} \mathrm{U}$ fission chambers are the contamination of ${ }^{235} \mathrm{U}$ in the $\mathrm{uDU}$ and the lack of availability of uDU. Earlier studies have shown that a ${ }^{235} \mathrm{U}$ content of about $4 \mathrm{ppm}$ had a manageable impact on the detector response (Cramer et al. 1976); higher levels of ${ }^{235} \mathrm{U}$ may be tolerable. UNLV has a sample of uDU with approximately $1 \mathrm{ppm}{ }^{235} \mathrm{U}$. The challenge for developing a uDU fission chamber is plating the uDU without introducing significant contamination from ${ }^{235} \mathrm{U}$. Previous UNLV research was focused on developing new plating techniques. For this research, we suggest using clean (low ${ }^{235} U$ contamination) versions of existing plating techniques, with UNLV focusing on the fabrication and testing of the uDU fission chamber.

The advantage of the ${ }^{4} \mathrm{He}$ recoil scintillator is significantly higher sensitivity to fast neutrons. Much like the uDU fission chamber, if successful, a ${ }^{4} \mathrm{He}$ scintillator may enable the reduction of neutron intensity, number of detectors, lead assembly size or measurement time. Unlike the uDU fission chambers, the ${ }^{4} \mathrm{He}$ scintillator has the potential to improve performance by at least two orders of magnitude. LANL, in collaboration with Duke University, has been developing a ${ }^{4}$ He scintillator for use with the LSDS. The collaboration recommends this development continue, and that testing on this new scintillator be conducted at LANL and RPI. 


\subsection{Risks and Mitigation}

The largest risk of this plan is the ability to use both a fresh fuel assembly and MOX material for the measurements. The two sets of materials have different requirements. The fresh fuel assembly is currently at a different RPI facility than the one that could conduct this research. RPI has begun the process to obtain the necessary license from the NRC to ship the material between the two sites.

The fresh MOX material presents a different level of challenges. The collaboration is currently engaged in discussions with SCK•CEN in Belgium for the use of fresh MOX rodlets that are 50 and $100 \mathrm{~cm}$ long, containing a variety of ${ }^{235} \mathrm{U}$ and ${ }^{239} \mathrm{Pu}$ content. The collaboration would like to use roughly 10 rodlets, which will have a total oxide-material mass of $3 \mathrm{~kg}$ containing approximately $150 \mathrm{~g}$ of plutonium. The intention is to borrow this material for the measurements, and then return them to Belgium so that disposition is not an issue. To use these rodlets, the collaboration needs to formalize arrangements to borrow the rodlets from SCK $\bullet \mathrm{CEN}$, arrange for the necessary licensing amendments for RPI, and arrange for the rodlets to be shipped to RPI and then back to SCK $\bullet$ CEN.

Another risk related to the use of the MOX fuel is its expense and the resulting level of funding required. At this point, there remain several expenditures of unknown magnitude that have not been included in this funding request. These include the cost of use of the SCK $\bullet$ CEN material and shipping of the material to and from the RPI. While a modest cost for the preparation of the necessary licensing has been included, another risk is that the licensing process will take longer and involve more effort than originally planned.

Several steps have begun to mitigate these risks. Preliminary discussions with the RPI radiation safety officer indicate that RPI should be able to receive the necessary license amendments for the MOX material. PNNL is currently engaged in discussions with AREVA to estimate the cost of shipping the material between Belgium and RPI. The challenge is to identify a cask that is suitable for handling the material that is certified in both Europe and the US. The size of the cask may limit the size of the rodlets to $50 \mathrm{~cm}$.

\subsection{Summary}

The LSDS collaboration recommends that the next demonstration measurement for the LSDS technique for assaying used fuel assembly be a pair of measurements. The first measurement will be to test the impact of self-attenuation using fresh fuel sub-assemblies. The second measurement will test the ability to extract fissile isotopes using fresh MOX fuel rodlets. As part of this effort, RPI will be the focus of the measurements, ISU will develop a thorium fission chamber, UNLV will develop uDU fission chamber, LANL will test the ${ }^{4} \mathrm{He}$ recoil scintillator detector concept, and both LANL and PNNL will continue to refine algorithms. Two possible funding options have been outlined, one assuming MPACT funding only, and the other assuming cost sharing with NEUP. 


\subsection{References}

Cramer, DS, RE Slovacek, EB Bean, and RG Luce. 1976. Lead Spectrometer for Non-Destructive Nuclear Fuel Assay. Report No. KAPL-M-7449, Knolls Atomic Power Laboratory, Schenectady, New York.

Daures, P, P Richir, B Cremer, H Ottmar, K Mayer, and U Blohm-Hieber. 2001. Commissioning and Routine Operation of the Laboratoire Sur Site. Presented at ESARDA Symposium on Safeguards and Nuclear Material Management, Bruges, Belgium, Joint Research Centre Institute for Transuranium Elements, Varese, Italy.

Humphrey, M. 2012. Email to GA Warren (PNNL) from Marc Humphrey (U.S. Department of Energy), "Spent Fuel Measurements." December, Richland, WA.

IPFM. 2012. Global Fissile Material Report 2011 -- Nuclear Weapon and Fissile Material Stockpiles and Production. Report No. 6, International Panel on Fissile Materials, Princeton, NJ.

Lemnios, ZJ. 2011. "Technology Readiness Assessment (TRA) Guidance." 20 pp. U.S. Department of Defense, Washington, D.C. 


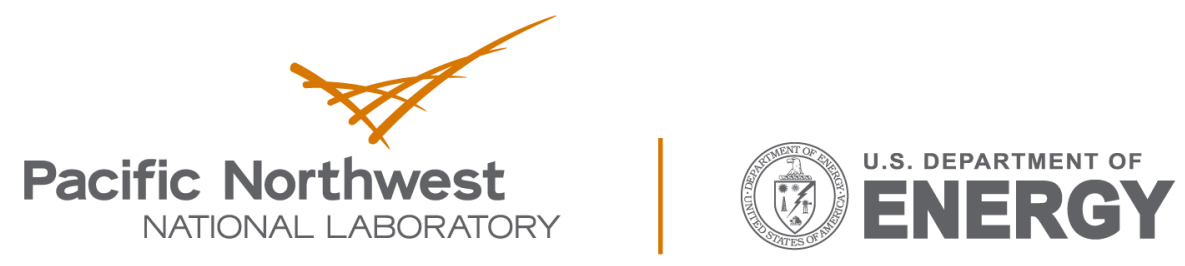

Proudly Operated by Battelle Since 1965

902 Battelle Boulevard

P.O. Box 999

Richland, WA 99352

1-888-375-PNNL (7665)

www.pnnl.gov 